\title{
Transitional self-disappear: the journey of cancer survivors to self re-coherence in a Middle East society
}

\author{
Mojtaba Dehghan ${ }^{1} \mathbb{D} \cdot$ Jafar Hasani $^{2} \cdot$ Alireza Moradi $^{2} \cdot$ Shahram Mohammadkhani $^{2}$
}

Received: 30 August 2021 / Accepted: 22 December 2021 / Published online: 27 January 2022

(c) The Author(s), under exclusive licence to Springer-Verlag GmbH Germany, part of Springer Nature 2021

\begin{abstract}
Purpose People who experience cancer often face serious and unpleasant challenges in understanding their past, present, and future. They think they have lost their lifetime, agency, and interpersonal relationships, and no longer know their bodies. These experiences can change survivors' perceptions of themselves. Therefore, the present study aimed to develop a deep theoretical understanding of the change of self in cancer survivors.

Methods Semi-structured interviews were used to collect data. Interviews were conducted with 17 cancer survivors, 2 oncologists, and 2 family members of survivors. In this study, grounded theory methodology was used to explore the process of understanding and experiencing "self" in cancer survivors.

Results The present study generated a model about the change of self, with the main concept called "transitional self-disappear," which is understandable based on the concepts of self-disruption (temporal disruption, highlighted body, interference in the agency, individual-self disruption, over-differentiation, relational self-disruption, and painful emotional experiences), self-reconstruction strategy, and quality of self-coherence, and occurs in the context of the cancer-based socio-cultural experiences and individual-environmental preparedness.

Conclusion This model illuminated the complex paths and roads of the survivors' journey from self-disappear to self reconstruction/re-coherence. A healthier experience of this journey can be facilitated by the transcendence of the "self" conceptualized in the past, and the promotion of specific (cancer-based socio-cultural experiences) and general (individualenvironmental preparedness) conditions.
\end{abstract}

Keywords Cancer $\cdot$ Self $\cdot$ Transitional self-disappear $\cdot$ Qualitative research · Grounded theory

\section{Introduction}

The healthy of the "self" requires the experience of the continuity of "self" [1-6]. This means that the self is an intra-psychological structure [1], and experiences and

Mojtaba Dehghan

mojtaba66dehqan@gmail.com

Jafar Hasani

hasanimehr57@yahoo.com

Alireza Moradi

moradi90@yahoo.com

Shahram Mohammadkhani

sh.mohammadkhani@gmail.com

1 Health Psychology, Kharazmi University, Tehran, Iran

2 Department of Clinical Psychology, Kharazmi University, Tehran, Iran understanding of life story in a continuous and chronological sequence [2-6]. The continuity of "self" is at the center of finding meaning $[4,7]$ and is also a vital issue for one's psychological well-being [5, 6]. But the horrific experience of cancer seems to disrupt the normal flow of life story and its sense of coherence because, in the presence of chronic illnesses, including cancer, a person's daily actions and expectations about his/her life change [8], the person feels that he/she does not have control in some areas of life [9], the person's relationship with his/her body changes [10,11], and confront with mortality and death [11]. Also, patients with cancer often have unmet social support requirements and emotional needs [12], while an important part of identity, and a person's knowledge and perception of herself are made in social relations [13].

A qualitative study of cancer survivors in Mexico found that they face challenges including cancer stigmas, distress from physical change, loss of control and attitude about 
planning, family as a supportive source, and financial problems [14]. In such circumstances, one may be required to future reappraisal [15] and reorganize his/her standards and beliefs and values system [16]; and perhaps it is because of the experience of such challenges that chronic illness leads to the imposition of changes and redefinition of patient roles and responsibilities [17]. Thus, the experience of cancer conditions may impose changes on a person's understanding of him/herself.

Thus, the issue that how is an understanding of self and its transformation process in patients with cancer necessitates conducting in-depth and first-hand qualitative studies. But, in the context of chronic illnesses, concepts related to change of identity/self have often been investigated in the studies of Western and developed countries researchers $[10,12,14,18,19]$, and they have not been considered in the socio-cultural context of the Middle East countries, especially Iranian society. However, the cultural and socioeconomic conditions of a particular society in which a person with cancer lives have some implications and meanings about the experience of life in the presence of cancer illness [17]. Therefore, understanding this process is very important in the cultural and socio-economic context of Iranian society. In this regard, Surbone [20] points out that cultural competence, which requires oncologists to be aware of their cultural values and beliefs, can lead to improved therapeutic outcomes and reduced disparities in cancer-related health care. Therefore, this study can help to understand the level of change and integration of "self" in the process of dealing with cancer and improve treatment interventions and care services for cancer survivors in middle eastern countries, especially Iran. According to what was said, the present study, which has used a qualitative method, addressed the question of how is the change of self in cancer survivors in the context of Iranian society.

\section{Methods}

In the present qualitative research, the design of systematic grounded theory $[21,22]$ was used. This study was conducted between July 21, 2020, and January 30, 2021. In the present study, the COREQ standard checklist [23] was used. The research population was cancer survivors referred to cancer treatment centers in Tehran (Iran) selected based on inclusion/exclusion criteria. Inclusion criteria included these cases: age range 20 to 50 years, informed and satisfactory readiness to participate in the research. Exclusion criteria also included: suffering from other chronic physical illnesses, substance use, and a history of imprisonment. Rapid cognitive changes that occur in childhood continue into adolescence and even into 20 years, and identity construction occurs during these years [24]. Therefore, only individuals over the age of 20 who have passed the identity construction period were included in the study. Also, ages over 50 are associated with increased cognitive impairment [25] which may interfere with the effect of the cancer experience on the definition of "self" and obscure the understanding of the process. Therefore the present study focused only on the age range of 20-50. Based on theoretical sampling, 21 participants (17 patients, 2 oncologists, and 2 family members) entered the research. Inclusion criteria for selecting family members included: Being as the main member of the family of the person with cancer, living with a person with cancer in a shared environment before and after the onset of cancer (at least 1 year), and having daily contact with a person with cancer. Exclusion criteria included a history of communication problems and conflicts with the person with cancer. Inclusion criteria for selecting oncologists include having 2 years of experience working with people with cancer. The exclusion criterion was not considered. Initially, an announcement was published about the purpose of the present research on social networks (Instagram, Telegram, and WhatsApp), and people with cancer were invited to participate in this research. Then, the purpose of this research and the ethical principles governing this study were explained to the volunteers, and among the volunteers, those who met the inclusion/exclusion criteria were included in the study. The information in Tables 1 and 2 includes the demographic characteristics of the participants, according to their self-reports.

In this study, semi-structured interviews were used to collect data. First, the interviews were developed based on a proposed four-axis framework [26, 27]: descriptive (e.g., What has happened in your life since you were diagnosed with cancer? When you found out you had cancer, what did you find out about yourself?), structural (e.g., How would you describe yourself as a person with cancer? What does "human with cancer" mean to you?), contrast (e.g., What do you think has changed since you got cancer? What will change if you find that your cancer is completely cured?), and evaluative (e.g., What thoughts and feelings do you have about yourself after cancer? How do you feel about yourself when you see your picture in the mirror?). Then, following the interview process, methods such as analytical questions to identify different codes and categories as well as specific questions to encourage the participant to explain his/her experience in more detail were used. The interviewer had no contact with the participants before beginning the study. Because of the prevalence of Coronavirus (COVID-19), and its risk, especially for people with cancer, the interviews were conducted via video call (WhatsApp). With the consent of each participant, his/her voice was recorded simultaneously using an audio recorder. Then, interviews were transcribed in Microsoft Word by someone out-of-study. To explore the cultural and socio-economic conditions in the 
Table 1 Demographic characteristics of patients with cancer

\begin{tabular}{|c|c|c|c|c|c|c|c|c|}
\hline Code & Age & Sex & Education & Marriage status & $\begin{array}{l}\text { Interview } \\
\text { duration }\end{array}$ & Cancer type & Time of diagnosis & Treatment status \\
\hline A & 36 & M & Associate & Married & $60 \mathrm{~min}$ & $\begin{array}{l}\text { Glioblastoma, right side of } \\
\text { head/grade } 4\end{array}$ & 2019, April & $\begin{array}{l}\text { Chemotherapy, do not } \\
\text { respond to treatment }\end{array}$ \\
\hline B & 47 & $\mathrm{~F}$ & Associate & $\begin{array}{l}\text { Divorce before } \\
\text { illness }\end{array}$ & $95 \mathrm{~min}$ & Cervical cancer, type I & 2018, April & End of treatment \\
\hline $\mathrm{C}$ & 41 & $\mathrm{~F}$ & Master & Married & $67 \mathrm{~min}$ & $\begin{array}{l}\text { Breast cancer/metastasing to } \\
\text { bone, sternum, and legs/ } \\
\text { grade } 2\end{array}$ & 2018, June & End of treatment \\
\hline $\mathrm{D}$ & 50 & $\mathrm{~F}$ & Diploma & $\begin{array}{l}\text { Divorce before } \\
\text { illness }\end{array}$ & $70 \mathrm{~min}$ & $\begin{array}{l}\text { Left ovarian cancer, metastas- } \\
\text { ing to thirteen points in the } \\
\text { body }\end{array}$ & 2018, September & $\begin{array}{l}\text { The patient canceled } \\
\text { the last } 2 \text { sessions of } \\
\text { chemotherapy }\end{array}$ \\
\hline $\mathrm{E}$ & 33 & $\mathrm{~F}$ & Bachelor & Married & $100 \mathrm{~min}$ & Cervical cancer, type I & 2017, September & End of treatment \\
\hline $\mathrm{F}$ & 42 & $\mathrm{~F}$ & Associate & Married & $58 \mathrm{~min}$ & $\begin{array}{l}\text { Right breast cancer/left breast } \\
\text { metastasis in the } 2017 \text { June }\end{array}$ & $\begin{array}{l}\text { 2017, June-2019, } \\
\text { May }\end{array}$ & $\begin{array}{l}\text { End of treatment of } \\
\text { the previous period/ } \\
\text { in the middle of the } \\
\text { treatment process of } \\
\text { the current period of } \\
\text { the illness }\end{array}$ \\
\hline G & 50 & $\mathrm{~F}$ & Associate & Married & $43 \mathrm{~min}$ & $\begin{array}{l}\text { Breast cancer/lymph nodus } \\
\text { metastasis/progressive type/ } \\
\text { grade } 3\end{array}$ & 2019, September & End of treatment \\
\hline $\mathrm{H}$ & 49 & $\mathrm{~F}$ & Bachelor & Married & $40 \mathrm{~min}$ & $\begin{array}{l}\text { Breast cancer, grade } 1 / \text { with the } \\
\text { possibility of lymph nodus } \\
\text { metastasis }\end{array}$ & 2019, February & End of treatment \\
\hline I & 31 & $\mathrm{~F}$ & Bachelor & Married & $59 \mathrm{~min}$ & $\begin{array}{l}\text { Acute myeloid leukemia } \\
\text { (AML) }\end{array}$ & 2019, August & $\begin{array}{l}\text { End of chemotherapy/ } \\
\text { on the waiting list for } \\
\text { stem cell transplanta- } \\
\text { tion }\end{array}$ \\
\hline $\mathrm{J}$ & 48 & $\mathrm{~F}$ & Bachelor & $\begin{array}{l}\text { Divorce before } \\
\text { cancer }\end{array}$ & $42 \min$ & Breast cancer/grade 3 & 2019, April & End of treatment \\
\hline $\mathrm{K}$ & 29 & M & Bachelor & Single & $80 \mathrm{~min}$ & Hodgkin's lymphoma/grade 1 & 2019, May & End of treatment \\
\hline $\mathrm{L}$ & 42 & $\mathrm{~F}$ & Diploma & Single & $62 \mathrm{~min}$ & Breast cancer/grade 2 & 2019, August & End of treatment \\
\hline M & 38 & M & Bachelor & $\begin{array}{l}\text { Marriage after } \\
\text { cancer }\end{array}$ & $48 \mathrm{~min}$ & $\begin{array}{l}\text { Testicular cancer/liver and lung } \\
\text { metastasis }\end{array}$ & 2010, July & End of treatment \\
\hline $\mathrm{N}$ & 48 & $\mathrm{~F}$ & Master & $\begin{array}{l}\text { Death of a } \\
\text { spouse before } \\
\text { cancer }\end{array}$ & $54 \mathrm{~min}$ & Breast cancer/grade 3 & 2020, May & $\begin{array}{l}\text { He has had a chemo- } \\
\text { therapy session so far }\end{array}$ \\
\hline $\mathrm{O}$ & 37 & $\mathrm{~F}$ & Diploma & Married & $57 \mathrm{~min}$ & Colon cancer/grade 3 & 2017, June & $\begin{array}{l}\text { End of treatment/doing } \\
\text { the course of radia- } \\
\text { tion therapy }\end{array}$ \\
\hline $\mathrm{P}$ & 49 & M & Diploma & Married & $44 \mathrm{~min}$ & Colon cancer/grade 4 & 2016, April & End of treatment \\
\hline Q & 43 & $\mathrm{~F}$ & Bachelor & Married & $65 \mathrm{~min}$ & $\begin{array}{l}\text { Breast cancer/recurrence after } \\
9 \text { years/grade } 3\end{array}$ & $\begin{array}{l}2016 \text { April and } \\
\text { recurrence in } 2020 \\
\text { July }\end{array}$ & $\begin{array}{l}\text { End of treatment of } \\
\text { the previous period/ } \\
\text { in the middle of the } \\
\text { treatment process of } \\
\text { the illness current } \\
\text { period }\end{array}$ \\
\hline
\end{tabular}

interview process, a question was asked at the beginning of the interview: "How was the story diagnosis of cancer about you, and how did you become aware of it?". In this section, participants usually pointed out the strengths and weaknesses of the health system in diagnosing the disease, supporting the patient, how to inform him, financial challenges, family/friend reactions. Also, at the end of each interview, the participant was asked, "What challenges or other issues does she/he want to talk about?". In addition, some of the four-axis interview questions evoked answers that reflected the socio-cultural and economic dimensions of their experiences. None of the participants in the study dropped out. The sampling reached saturation from patient no. 15 (interviewee $\mathrm{O}$ ), and the codes extracted from interviews 16 and 
Table 2 Demographic characteristics of specialists and families of patients with cancer

\begin{tabular}{|c|c|c|c|c|}
\hline Code & Age & Sex & Interview duration & \\
\hline $\mathrm{R}$ & 49 & M & $40 \mathrm{~min}$ & Oncologist \\
\hline S & 44 & M & $42 \min$ & Oncologist \\
\hline $\mathrm{T}$ & 36 & $\mathrm{~F}$ & $65 \min$ & $\begin{array}{l}\text { Spouse of a person with } \\
\text { cancer }\end{array}$ \\
\hline $\mathrm{U}$ & 30 & $\mathrm{~F}$ & $52 \min$ & Sister of a person with cancer \\
\hline
\end{tabular}

17 did not have added value for the explanatory capability of the extracted model. Also, 2 oncologists and 2 family members of patients with cancer were interviewed. This action paved the way for the formation of triangulation, by providing evidence from numerous sources [22, 28]. However, the analysis of the data of these four interviewees (family members and oncologists) did not have the added explanatory capability and adequacy for the research, which indicated saturation. Therefore, the interview with these people was not continued. The interview was conducted by the first author (Interviewer profile: Male; Ph.D. in Health Psychology; Psychotherapist; Passing a training course in qualitative research and grounded theory). Initial coding was done by the first author and then reviewed by other authors. Then, the extracted codes and categories were reviewed by two out-ofstudy psychology $\mathrm{Ph}$.Ds. The interview grid was the same in survivors, family members, and oncologists. All interviews were conducted in Persian and analyzed in Persian. Then, the research report was translated into English. In this process, two independent English translators were used, and then, in consultation with the third translator who had a Ph.D. in psychology, the final English translation of the research report was provided.

In this study, researchers maintained their theoretical sensitivity. The researchers tried to use their previous knowledge from the psychological literature (based on the biopsychosocial approach) and professional experiences to determine what happens in the data. By going beyond mere descriptions, the researchers tried to abstract the similarities between the different codes, concepts, and categories, and compare and modify them in subsequent interviews. Also, by abstracting from the interviewers' statements, the interaction between the categories and their position in relation to each other was identified in a process coding to achieve theoretical integration. The process of collection and analysis of research data has been drawn in Fig. 1.

\section{Results}

In the present research, five categorical clusters appeared: Self-disruption, Cancer-based socio-cultural experiences, Individual-environmental preparedness, and
Self-reconstruction strategies, and the Quality of self-coherence; and the relationship between these five concepts have been understood by the major concept of "transitional selfdisappear." Categories and components of 5 clusters can be seen in Table 3.

Self-disruption The concept of "self-disruption" includes several various components that indicate a kind of cracking and gap in the experience of self and the emotions associated with this experience. By abstracting from the data, the category of self-disruption seems to be an antecedent to the phenomenon of "transitional self-disappear." In the following, each of its 7 categories is described:

1. Temporal disruption refers to the point that by touching and a close encounter with death, patients think they have lost the past, and the phenomena of cancer and death are dominant on their present time, and the future is ambiguous and dark: "Those early days when I was newly infected the future was dark for me. I do not want to think about the future now. I thought I would not be alive any longer for another four months (Interviewee $\mathrm{N})$," and "According to some patients, the situation of cancer is 'as if I am a rock that has been left on top of a mountain and I know that I will collapse at the bottom of this mountain', and then it will be in ambiguity (Interviewee R)."

2. Highlighted body refers to the point that due to severe physical experiences the person's body is in the center of his/her attention and monitoring more than before, and it seems that a rift is created between the person and his/her body: "I think I am an imperfect creature right now. That day I told my husband that I am no longer a woman at all, so I am imperfect (Interviewee E)," and "After my wife got cancer, her body became weak, and now my wife suffers from impotence and sexual weakness (Interviewee T)."

3. Interference in agency reflects the feeling in a patient that she/he has lost agency and control over his/her roles, tasks, and actions of life (individual, social and occupational): "Compared to before my illness, I lost a lot of ability to do tasks. Well, one of my hands does not work much as before. I have to be dependent on others (Interviewee J)," and "Cancer transmits some of the feelings to the person that is not really in the patient's control. I think what is going on in the person is that 'we (after this disease) have nothing left in our hands' (Interviewee R)."

4. Individual-self disruption indicates that many people with cancer state that they are different from someone they have been in the past in terms of interests, goals, inner values, and so on: "I am very different from the person I was before; one varies very much. I was com- 


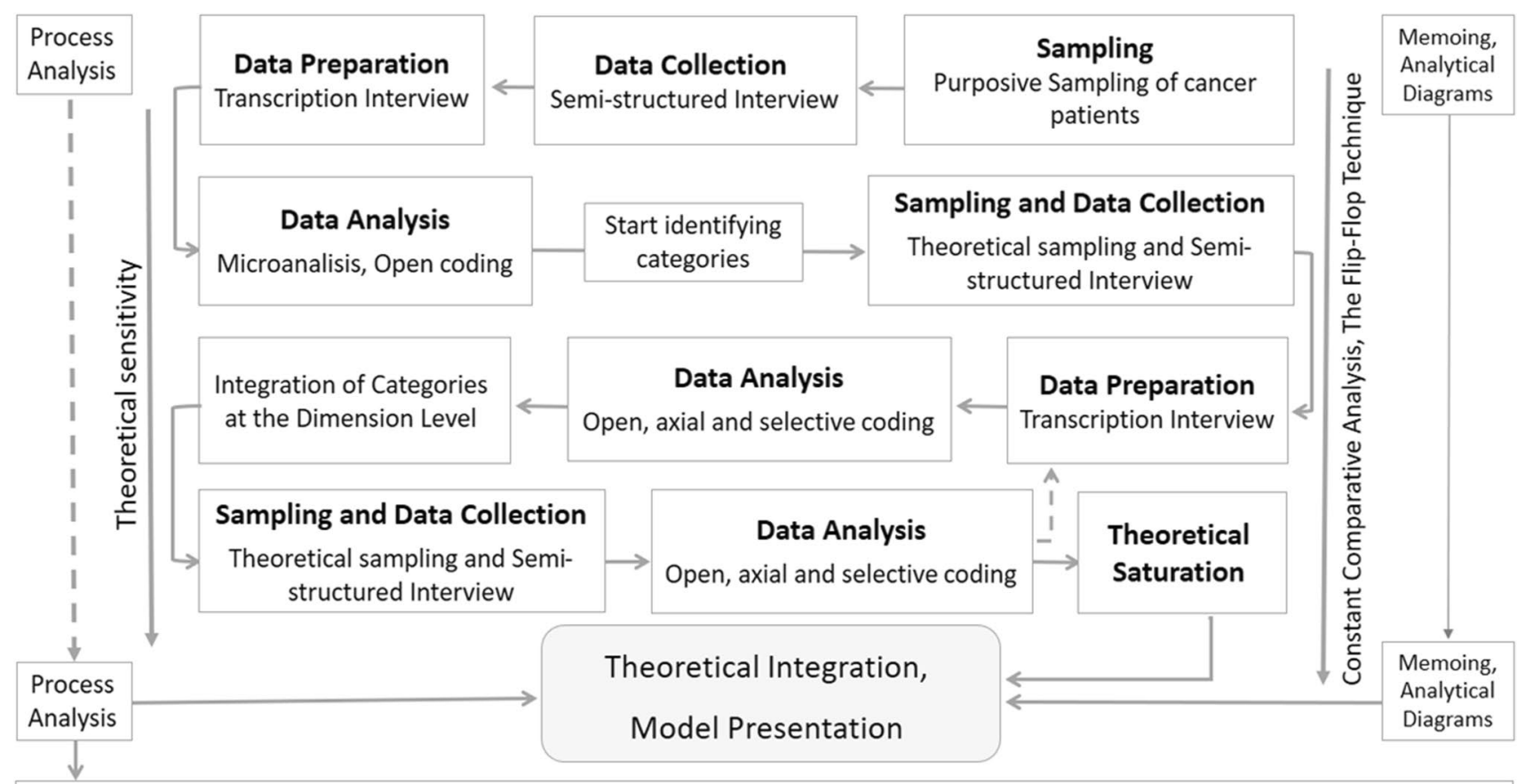

The accuracy and reliability strategies in research process: In member checking; rich and thick descriptions; searching for deviant cases; record the process and stages of the study; checking transcripts; methodological coherence; triangulation; ensuring that codes definitions do not deviate (reviewed by two out-of-study Ph.Ds. in psychology); and continuous comparison of data with codes and using remembrance writing).

Fig. 1 Visual representation of the research data collection and analysis process

pletely another person before. I was very good. I am not like the previous person at all (Interviewee B)," and "My husband has been feeling very, very weak about herself since he got cancer (Interviewee T)."

5. Over-differentiation means that when people are affected by cancer, are faced with the ontological question, "Why me? Why was I chosen to have this illness and not others?" Also, they feel that their experiences and flow of life have become very different and unusual, and their distinction from others has increased: "I am very different from people who do not suffer, in terms of my ability, in terms of my beauty (Interviewee J)," and "When my sister found out she had cancer, she was always faced with this question, 'Why me? of all the people, why me?' (Interviewee U)."

6. Relational self-disruption indicates the disturbance, being threatened, and the fragmentation of a person's definition of themselves in relation to others; because after getting cancer, significant relationships and mutual bonds of an individual are damaged. In addition, the affected person with the idea of his/her possible absence in the future has important concerns about important relatives and his/her relationships with them: "Ninety percent of people with cancer, like me, are those who are not seen by those around them, and have put them aside (Interviewee B)," and "Some relatives and friends of a person with cancer, when they find out that person has cancer, do not go to see what is happening, do not call, do not follow up, while that person is waiting for support by them (Interviewee S)."

7. Painful emotional experiences refer to a range of unpleasant emotional experiences that occur after getting cancer and damage to various dimensions of the self: "Ever since I got cancer, these feelings have generally been inside me, perhaps a deep nostalgia, perhaps a deep disillusionment, frustrated heart, perhaps a heavy disgust- Interviewee L)," and "When she realized that she had cancer, she became very angry with the world and became very angry with God (Interviewee U)."

Cancer-based socio-cultural experiences This concept means a set of socio-cultural experiences (a set of attitudes, discourses, and reactions in society towards cancer) based specifically on the experience of cancer that patients face. These experiences can affect the sufferer's self, which is now undergoing a kind of transformation. In the following, each of its 6 categories is described:

1. Unexpectedness is related to this cultural attitude that patients considered themselves far from cancer because everyone believes only certain people get cancer, that is, people who have behaved wrongly and sinfully in 
Table 3 Clusters, categories, and components of the "transitional self-disappear" model

\begin{tabular}{|c|c|c|}
\hline Cluster & Category & Component \\
\hline \multirow[t]{7}{*}{ Self-disruption } & Temporal disruption & $\begin{array}{l}\text { Touch of death, dark future, confusion present, dissolution of the } \\
\text { past }\end{array}$ \\
\hline & Highlighted body & $\begin{array}{l}\text { Physical symptoms (severe pains, fatigue, and so on), sexual } \\
\text { problems, physical dysfunction, bodily losses, damage to beauty, } \\
\text { the spread of illness in the body, the continuation of illness in } \\
\text { the body, an external organ (such as a cane) to the body, weight } \\
\text { change, and the body in the center of attention }\end{array}$ \\
\hline & Interference in agency & $\begin{array}{l}\text { Lack of personal control, dependent on others, lack of interpersonal } \\
\text { control, and lack of job agency }\end{array}$ \\
\hline & Individual self-disruption & $\begin{array}{l}\text { A feeling of inner change, confusion, worthless feeling, cognitive } \\
\text { weakness, and doubt about personal interests and goals }\end{array}$ \\
\hline & Over-differentiation & $\begin{array}{l}\text { "Why me?" question, becoming unusual, and increased differentia- } \\
\text { tion from others }\end{array}$ \\
\hline & Relational-self disruption & $\begin{array}{l}\text { Changing meaningful relationships, abandonment/rejection by oth- } \\
\text { ers, intra-interpersonal contradictions (contradictory perception of } \\
\text { himself and others of his current feelings and abilities), and Family } \\
\text { concerns }\end{array}$ \\
\hline & Painful emotional experiences & $\begin{array}{l}\text { Fear, despair, hatred, anger, anxiety, shame, guilt, sadness, regret, } \\
\text { and loneliness }\end{array}$ \\
\hline \multirow[t]{6}{*}{ Cancer-based socio-cultural experiences } & Unexpectedness & - \\
\hline & Cultural attitudes & Cancer as a catastrophe, and death \\
\hline & Illness explanations & $\begin{array}{l}\text { Action retribution, destiny, the consequence of unhealthy behaviors, } \\
\text { and psychological stresses }\end{array}$ \\
\hline & Cancer metaphors & Cancer as an opponent/enemy, uninvited guest, and inspiring \\
\hline & Social feedback & $\begin{array}{l}\text { Social judgments, weakening supports, annoying curiosities, and } \\
\text { hateful compassion }\end{array}$ \\
\hline & Unpleasant hospital interactions & $\begin{array}{l}\text { Horrific predictions, drug consequences, and long-term post-treat- } \\
\text { ment consequences }\end{array}$ \\
\hline \multirow[t]{3}{*}{ Individual-environmental preparedness } & Past characteristics/strategies & Traits, coping styles, and values \\
\hline & Financial problems & - \\
\hline & Health system shortcomings & $\begin{array}{l}\text { Inadequate training, weakness in counseling, specialists' ambiguous } \\
\text { speech, misdiagnosis, and drug/treatment deficiencies }\end{array}$ \\
\hline \multirow[t]{5}{*}{ Self-reconstruction strategy } & Redefining theme & $\begin{array}{l}\text { The family theme, spiritual theme, personal theme: self-idealization } \\
\text { (building a resilient and heroic self-image against cancer) and } \\
\text { self-centeredness (special emphasis on one's needs, compared to } \\
\text { past neglects), and symbolic survival (doing something or creating } \\
\text { something that makes a person symbolically stable and alive) }\end{array}$ \\
\hline & Agency-seeking & $\begin{array}{l}\text { Resuming activities, showing his/herself as normal, and fighting } \\
\text { illness }\end{array}$ \\
\hline & Redefining Identity & $\begin{array}{l}\text { Redefining the body, acceptance of illness identity, and redefining } \\
\text { goals }\end{array}$ \\
\hline & Denial of illness identity & - \\
\hline & Considering illness as a stage & - \\
\hline \multirow[t]{2}{*}{ Quality of self-coherence } & Adjusted coherence & Awareness, valuing life, patience, and relationship promotion \\
\hline & Unadjusted coherence & $\begin{array}{l}\text { Isolation, interpersonal sensitivity, irritability/aggression, gloom, } \\
\text { and wanting death }\end{array}$ \\
\hline
\end{tabular}

their lives. So everyone knows him/herself away from cancer and experiences it unexpectedly: "One always thinks that this illness is for others and never suffers from such a thing-Interviewee C)," and "People who do not get cancer live their lives, and they always do, and they think that events, deaths, and illnesses are for others (Interviewee N)."
2. Cultural attitudes indicate the viewpoints and ideas of community members and those around the survivor about "cancer," which included two ideas and beliefs: cancer as a catastrophe (getting cancer is a very big and unsolvable catastrophe) and as death (getting cancer means the end of life and death). "People around me said that it seems that a person who refers to the hospital 
for cancer will really die (Interviewee K)," and "I think cancer is a shock in a person's life, but as much as the society is afraid of cancer and see it as very big, the disease itself is not so scary (Interviewee Q)."

3. Illness explanation describes that cancer is usually considered retribution of past errors and sins, being chosen by the destiny (God, fate, world, and so on), the consequence of unhealthy behaviors and psychological stresses: "In our culture, it is believed that whoever does the wrong and sinful thing will finally get the answer (Interviewee O)," "Cancer is just a choice by fate; I might say the choice of God or the choice of the universe. And I definitely have a very bad feeling about it that I was so miserable that the lot fell upon in my name (Interviewee E)," and "In my opinion, cancer does not come to a person all at once, but it is a thing that has a history; It is either based on nervousness, or trauma, or something else (Interviewee A)."

4. Cancer metaphors refer to the representation that each patient has of their illness. These representations seem to be shaped by social beliefs and feedback from others about one's illness. cancer metaphors were expressed by participants in three ways: (1) cancer as an "opponent/enemy" (rival and enemy who has attacked the person): "Cancer illness is a real enemy that is hitting from within (interviewee M)." (2) Cancer as an "uninvited guest" (uninvited guest who is not an enemy but it is not pleasant either): "One day I gathered all my colleagues and told them I have an uninvited guest that I'm not going to fight, but I have to cope with (Interviewee H)." (3) Cancer as an "inspiring" (a messenger that wants to inform the person): "Cancer is a thing that wants to show us the value of our health value or our existential value (Interviewee J)."

5. Social feedback indicates the unpleasant reactions and behaviors of those around towards the "person" with cancer. This category includes (1) social judgments: "A man said, It is better that he (A child with cancer) died, believe that his mother lives easier from now on. I hated what he said (Interviewee E)," (2) debilitating support: "The words that others say to me, 'You sit down now and do not need to get up to do something, your mood is bad, do not work now, bother me. And I hate that they consider me weak and sick (Interviewee D)," (3) annoying curiosity: "The people and my friends call me and ask 'How annoyed were you? When are you going to have surgery? So, what do you have to do, now?'; But I really don't like to talk about it (Interviewee G)."

6. Unpleasant hospital interactions explain unpleasant conversations and interactions between the patient and the treatment team and others about cancer and form a part of the survivors' lives; and included "negative feedback from the doctor, nurse, and hospital employees" to the patient and his/her needs as well as some "unpleasant messages about the illness" to the patient: "The doctor told me that you would experience severe symptoms, and you would not survive for more than six months. He said we would start with chemotherapy but only six months (Interviewee J)," and "When I went to see my husband at the cancer unit in the hospital, the behavior of the cancer unit nurses were not at all appropriate for these patients, and unfortunately, they had no knowledge of the conditions and concerns of the cancer patients (Interviewee T)."

Individual-environmental preparedness This concept includes a set of general individual or social conditions and factors that are not specific to the experience of cancer, but affect the way a person encounters what has happened. In the following, each of its 3 categories is described:

1. Past characteristics/strategies explain the previous coping styles, traits, and values that have developed in a person over the years, and now that a person has the disease, it can also affect in facing cancer in exposure to the main phenomenon: "I am generally a person who tries to cope with the conditions, that is, I was the same before the cancer illness, I do not take it hard (Interviewee C)," and "When people receive a cancer diagnosis, all the values that they have grown up with since childhood help them after a while, to adapt to the situation (Interviewee S)."

2. Financial problems explain the very high costs of treatment and the financial problems of people at the time of getting cancer, that can affect how a person copes with the illness and its consequences: "I had to sell my daughter's golds, for chemotherapy (Interviewee K)," and "Financial problems and medical expenses really increase the pressure of the disease and even the fear of being disabled and it is very annoying (Interviewee U)."

3. Health system shortcomings refer to the set of inefficient programs, functions, and actions of the health system and its activists (including officials, specialists, nurses, service groups, and so on) that are not limited to cancer illness, but can affect the confrontation experiences and procedures of people with cancer: "Unfortunately, doctors and nurses do not provide enough education about the course of cancer symptoms, and there is no proper nutrition counseling (Interviewee G)," and "When we went to the doctors, they did not spend enough time and answered very briefly and concisely, which made us more worried (Interviewee T)."

Self-reconstruction strategy This concept refers to strategies that are intentionally or unintentionally used to reconstruct 
the "self" that has been disrupted and disappeared in facing cancer. In the following, each of its 5 categories is described:

1. In the redefining theme strategy, after getting an illness, one tries to find a new theme or redefine some former possessions in a different and new way to make the "self" coherent around it: "I feel that my mission is just to get these two children to a stage in life where they can be independent, and no longer depend on or need anybody, then I have nothing to do in this world (Interviewee O)."

2. In the agency-seeking strategy, a person tries to regain a sense of agency and control over life by resuming activities, showing his/her "self" normal, and fighting his/her illness. The consequence of this effort is a feeling of "self" again: "I exercised during chemotherapy while the doctors said you should not do it. I, by doing my activities, wanted to show that I was still alive (Interviewee M)."

3. In the redefining Identity strategy, after facing an illness crisis, people try to redefine the position of the body in their understanding of self ("Now, I feel I have to treat my body and those parts that are affected by cancer, like a child that we caress when she/he is upset and crying. Interviewee C"), accept the illness identity as a part of their identity ("Given that this illness is an experienced part of my life, I will share it with that the person I am going to be with later. Interviewee L"), and emulate the heroes who have won the battle against cancer ("During treatment, I became acquainted with Lance Armstrong's book, and because my illness was exactly the same as his, and I can say that the book became the Quran of my life, that I did all the things he had done-Interviewee M"), and reconstruct themselves.

4. In the denial of illness identity strategy, one tries to reform and reconstruct the fracture and disruption of "self" by denying cancer and what has happened: "From the day I realized that I was sick, I did my best to avoid anybody who has cancer. I do not want to, I did not want to accept at all that I am one of them (Interviewee E)."

5. In the strategy of considering illness as a stage, regarding cancer as one of the stages of life, one tries to integrate this experience with other stages and periods of life, in this way to redefine her/himself life story: "When I finished the chemotherapy, I cut my hair short and took a photo and posted a story on Instagram, telling all my friends, family and acquaintances that I was going to start the new stage of my life (Interviewee L)."

Quality of self-coherence The quality of self-coherence explains the consequences that occur after experiencing self-disruption and applying strategies. By abstracting data, these consequences are defined in a range from adjusted to unadjusted coherence:

1. Adjusted coherence includes a set of healthy and adaptive consequences that lead one to believe that after cancer, her/his life has become meaningful and directional: "Now I understand how much a person loves life. At that time, life was not valuable to me (Interviewee I)."

2. Unadjusted coherence is a set of non-adaptive consequences, and it seems that the survived person has a confused definition of "self" leads one to believe that her/his life no longer has a recognizable meaning and purpose: "I no longer have the vivacity I had before, I have no previous mood. In this situation, I'm isolated and bored (Interviewee B)."

Transitional self-disappear This study developed the substantive model of "transitional self-disappear" to explain how people understand the "self" after getting cancer (see Fig. 1). This title was abstracted from the interviewees' descriptions and relationships between five major concepts. Indeed, Experiencing cancer and facing the issue of death makes people feel that the present time is a painful limbo that cuts the connection between the past and the future. That is, disruption is created in the temporary aspect of the self. This disruption and disconnection between the past, the present, and the future occur in various dimensions of understanding of self, including agency, physical, intrapersonal, relational and social, and emotional aspects. Therefore, in facing cancer, numerous aspects of experiencing and understanding the "self" are damaged and disrupted, and that previous "coherent and integrated self" is suddenly faded and lost. However this situation is not necessarily stable, rather self-disappear occurs transiently, meaning that self-disappear is an annoying but transitional stage to enter new and different conditions of life. And it is the result of self-reconstruction strategies and occurs in the context in which one lives (cancer-based socio-cultural experiences, and individual-environmental preparedness). The process of transitional self-disappear has been drawn in Fig. 2.

\section{Discussion}

This qualitative study was conducted to explore the process of change of self in people with cancer. According to the present study, at the time of an unexpected encounter with cancer, people experience a "temporal disruption"; meaning that they lose the sense of self-continuity over time. They suddenly think whatever they have built in the past is lost and there is no future to build. This is consistent with the previous finding that has shown people with cancer expose existential challenges in their relationship 


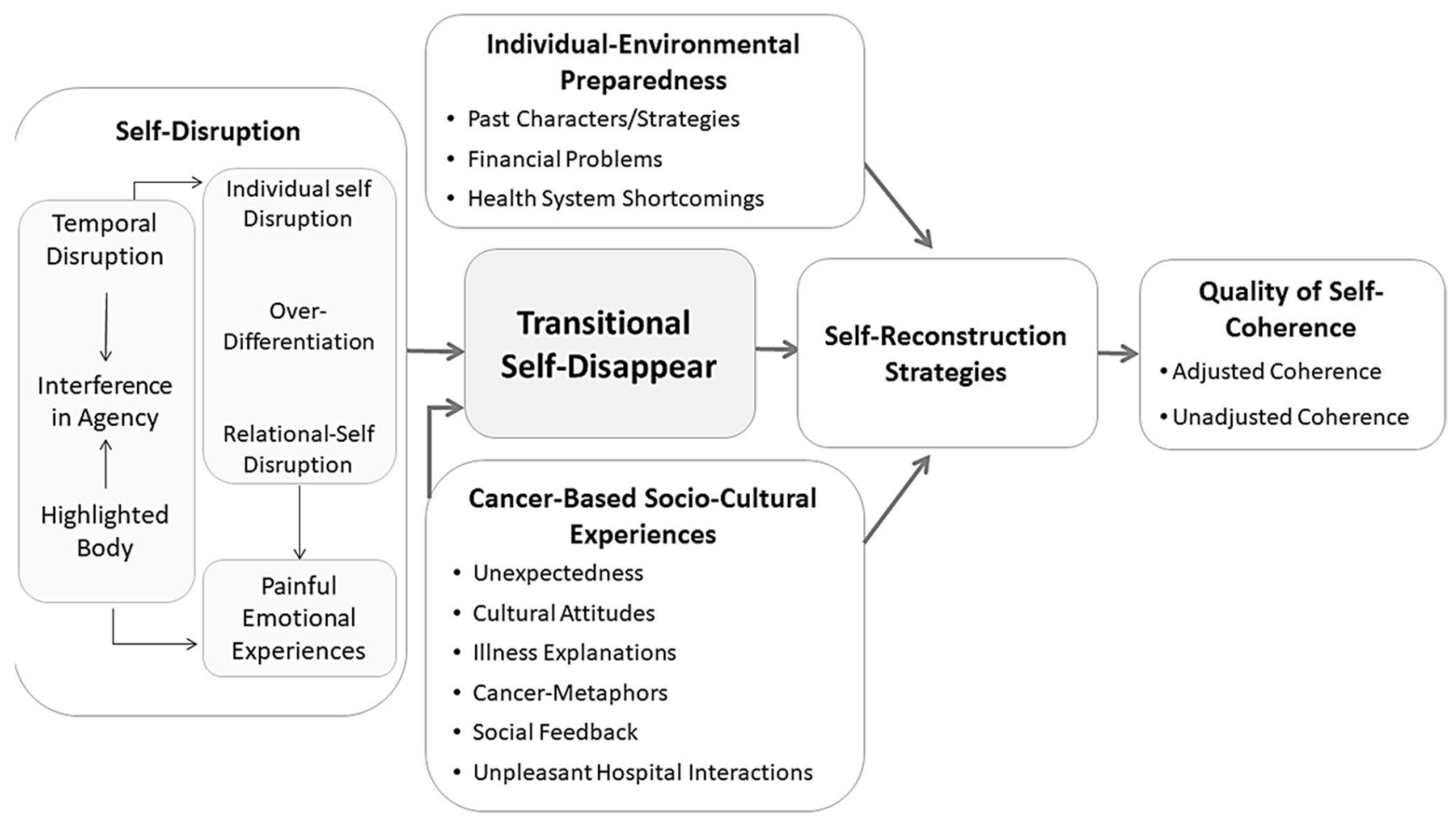

Fig. 2 Model of "transitional self-disappear" in the study of cancer survivors

to time [11]. Therefore, it seems that the sense of self that connects the past to the present and future of a person has disappeared.

Also, getting cancer is associated with some physical consequences (such as physical dysfunction, damage to beauty, the spread of illness in the body, the continued presence of the illness in the body, and so on), which attack the person's previous understanding of his/herself. Probably the reason for such an experience is because the body becomes the center of attention and is considered by the person more than before, which changes the person's interaction with his/ her body. Besides, following physical changes caused by cancer, people experience bodily doubt, and their previous assumptions about the relationship between the body and the "self" and their sense of wholeness are disturbed. Some previous studies [11,14] also support this idea.

After the occurrence of such experiences of chronological disruption and body highlighted for the affected person, the sense of control and agency of "self" fades and is distorted. The patient, as a result of changes and losses in the experience of "self," is both confused and thinks that his/her life story is different from the life story of the person he/she was before and that his/her difference with others have proliferated because he/she is no longer an ordinary (normal) human being according to the definition of the culture and society in which he/she lives. One of the important experiences in this regard that has serious effects on the experience of "self" in chronic illness conditions is a change in a person's daily habits.

Because of these unpleasant experiences and social reactions to a person's illness, his/her relationships with others diminish or change, and he/she experiences cases like isolation and loneliness. Thus, consistent with the study of Tarbi and Meghani [11], such experiences can impair the relational self, which is related to reciprocal interactions, intimacy, friendships. The study of Moore et al. [29] has shown that social isolation predicts the overall survival of patients with cancer. The sum of these experiences threatening the integrity and coherence of the "self" is associated with a range of unpleasant emotions (such as fear, anger, hatred, grief, and so on).

But the findings seem to show that the journey of patients with cancer does not end here. Rather, self-disappear provides an opportunity for the sufferer to relinquish the understanding and narration he/she already had of him/herself, and by transcending from the living past and the imagined future, he/she reconstructs and redefines the "self." The experience of trying to reconstruct the identity of self by cancer survivors has also been reported in the study of Harkin et al. [12]. Patients with cancer try for self-reconstruction and use different strategies for this purpose. For example, redefining theme and agencyseeking strategies can be ways to retrieve thematic coherence and retrieve the individual "self." Consistent with the results of Tiedtke et al. [30] on the return of patients with cancer to jobs, this finding seems to show the importance of increasing 
the sense of agency in cancer survivors. Besides, redefining identity through the acceptance of cancer-related experiences as a part of the identity of "self" is used by survivors for a variety of purposes, such as reforming chronological disruption, reconstructing relational-self, and reducing over-differentiation. These strategies can be efficient or inefficient depending on the situation and the amount of use.

Ultimately, after a long period that people ignore their chronic illness, and know it insignificant, struggle with it, or compromise with it, they reach the sense of wholeness again, that is, the unity of "self" and the body versus loss [10], and they can experience self-re-coherence. Thus, self-disappear is not a permanent experience, rather it is a stage of transient, and each person experiences it under the impact of the type of strategies and the conditions of his/her experiences.

The conditions of the experience of patients with cancer and survivors can be examined at two general (overall) and specific levels. The general level includes past characters and the previous coping strategies of the individual and macrosocial conditions (including the individual's financial problems and the extent of the health system shortcomings), that is not limited to the experience of cancer and the experience of transitional self-disappear but can affect how to face it. But the condition limited to experiencing cancer (specific level) includes attitudes, conversations, and actions that are solely specific to cancer and the person with cancer.

One of the implications of the present study is that in assessing the degree of adjustment of people with cancer, it can be determined that what extent each of the components of "self-disruption" has occurred in him; for example, how much the sense of agency of the person has been disturbed, the body has been highlighted, and the integrity and continuity of the person's narrative chain of his/herself that have been disturbed. Also, the person with cancer can be helped to redefine autobiographical memories, life goals, and future plans in a way that, while not denying the real changes caused by cancer, strengthens the coherence and integrity of the identity. In addition, it seems that if the policies of the health system include "education of the medical team and family of people with cancer," "more attention to the necessary and sufficient medical and psychosocial services for people with cancer," "changing the socio-societal beliefs and attitudes about cancer," and "cancerrelated financial problems," people with cancer will experience the path of self-destruction and self-reconstruction more easily, and go through it more successfully.

\section{Conclusion}

Few qualitative studies have examined the process of changing various components of "self" in cancer survivors, and especially in the socio-economic conditions of Iran, no research has been done so far. However, the process of changing the "self" can determine the degree of adjustment of a person to new living conditions in the context of their illness. The rich data and findings obtained from this study led to the illumination of the process and path of change of "self" in survivors. The findings also show that intrapersonal (e.g., past values and personality) and extrapersonal factors-both at the macrolevel (e.g., macro-social policy and economic conditions) and at the near and specific level (such as changes in quality of interpersonal relationships)—can affect the changes and reconstruction of "self" of people with cancer. The consistency of the findings with the theoretical and research literature indicates the accuracy and precision of the findings. The findings of the present research should be interpreted and used with caution because although it was tried to examine as much as possible the diversity of experiences, but interviews with survivors were limited to a few specific types of cancer.

Acknowledgements We appreciate all those who cooperated in this study, especially the participants who spent their time and attention for interviews in this research.

Author contribution Conceptualization: MD, JH. Data curation: MD, JH. Data analysis: MD. Investigation: all authors. Writing original draft: MD. All authors commented on previous versions of the manuscript. All authors read and approved the final manuscript.

Data availability Not applicable.

Code availability Not applicable.

\section{Declarations}

Ethics approval Approval was obtained from the faculty of psychology and education of Kharazmi University. The procedures used in this study have adhered to the tenets of the Declaration of Helsinki.

Consent to participate Verbal informed consent was obtained before the interview.

Consent for publication Verbal informed consent was obtained before the interview.

Conflict of Interest The authors declare no competing interests.

\section{References}

1. Kohut H (1971) The analysis of the self: a systematic approach to the psychoanalytic treatment of narcissistic personality disorders, 11 th edn. International University Press. I N C, Connecticut

2. Habermas T, Bluck S (2000) Getting a life: the emergence of the life story in adolescence. Psychol Bull 126(5):748-769. https:// doi.org/10.1037/0033-2909.126.5.748

3. Bluck S, Habermas T (2001) Extending the study of autobiographical memory: thinking back across the lifespan. Rev Gen Psychol 5:135-147. https://psycnet.apa.org/doi/10.1037/1089-2680.5.2. 135 
4. Singer JA (2004) Narrative identity and meaning making across the adult lifespan: an introduction. J Personal 72(3):437-459. https://psycnet.apa.org/doi/10.1111/j.0022-3506.2004.00268.x

5. McAdams DP, McLean KC (2013) Narrative identity. Curr Dir Psychol Sci 22(3):233-238. https://psycnet.apa.org/doi/10.1177/ 0963721413475622

6. McAdams DP (2015) The art and science of personality development. Guilford Press, New York3

7. Singer JA, Bluck S (2001) New perspectives on autobiographical memory: the integration of narrative processing and autobiographical reasoning. Rev Gen Psychol 5:91-99. https://psycnet. apa.org/doi/10.1037/1089-2680.5.2.91

8. Becker G (1994) Metaphors in disrupted lives: infertility and cultural constructions of continuity. Med Anthropol Q 8(2):383-410. https://doi.org/10.1525/maq.1994.8.4.02a00040

9. Mattingly C, Garro LC (2000) Narrative and the cultural construction of illness and healing. University of California Press, London

10. Charmaz K (1995) The body, identity and self. Sociol Q 36:657680. https://psycnet.apa.org/doi/10.1111/j.1533-8525.1995.tb004 59. $\mathrm{x}$

11. Tarbi EC, Meghani SH (2019) Existential experience in adults with advanced cancer: a concept analysis. Nurs Outlook 67(5):540-557. https://doi.org/10.1016/j.outlook.2019.03.006

12. Harkin LJ, Beaver K, Dey P, Choong K (2017) Navigating cancer using online communities: a grounded theory of survivor and family experiences. J Cancer Surviv 11:658-669. https://doi.org/10. 1007/s11764-017-0616-1

13. Sedikides C, Gaertner L, Luke MA, O'Mara EM, Gebauer JE (2013) A three-tier hierarchy of self-potency: individual self, relational self, collective self. In: Olson JM, Zanna MP (eds) Advances in experimental social psychology. Elsevier Academic Press, pp 235-295

14. Knaul FM, Doubova SV, Robledo MCG, Durstine A, Pages GS, Casanova F, Arreola-Ornelas H (2020) Self-identity, lived experiences, and challenges of breast, cervical, and prostate cancer survivorship in Mexico: a qualitative study. BMC Cancer 20:577. https://doi.org/10.1186/s12885-020-07076-w

15. Brown P, de Graaf S (2013) Considering a future which may not exist: the construction of time and expectations amidst advancedstage cancer. Health Risk Soc 15(6-7):543-560. https://doi.org/ $10.1080 / 13698575.2013 .830081$

16. Sprangers MAG, Schwartz CE (2000) Integrating response shift into health-related quality-of-life research: a theoretical model. In: Schwartz CE, Sprangers MAG (eds) Adaptation to changing health: response shift in quality-of-life research. American Psychological Association, Washington, pp 11-23

17. Pesantes MA, Somerville C, Singh SB, Perez-Leon S, Madede T, Suggs S, Beran D (2020) Disruption, changes, and adaptation: experiences with chronic conditions in Mozambique, Nepal and
Peru. Global Public Health 15(3):372-383. https://doi.org/10. 1080/17441692.2019.1668453

18 Hubbard G, Kidd L, Kearney N (2010) Disrupted lives and threats to identity: the experiences of people with colorectal cancer within the first year following diagnosis. Health 14(2):131-46. https://doi.org/10.1177/1363459309353294

19. Cheung SY, Delfabbro P (2016) Are you a cancer survivor? A review on cancer identity. J Cancer Surviv 10(4):759-771. https:// doi.org/10.1007/s11764-016-0521-z

20. Surbone A (2008) Cultural aspect of communication in cancer care. Support Care Cancer 16(3):235-240. https://doi.org/10. 1007/s00520-007-0366-0

21. Anselm S, Corbin J (1990) Basics of qualitative research: grounded theory procedures and techniques. SAGE Publications, Newbury Park

22. Corbin J, Anselm S (2015) Basics of qualitative research: techniques and procedures for developing grounded theory, 4th edn. SAGE Publications, Los Angeles

23. Tong A, Sainsbury P, Craig J (2007) Consolidated criteria for reporting qualitative research (COREQ): a 32-item checklist for interviews and focus groups. Int J Qual Health Care 19(6):349_ 357. https://doi.org/10.1093/intqhe/mzm042

24. Stangor C, Walinga J (2014) Introduction to psychology-1st, Canadian. BCcampus, Victoria

25. Pais R, Ruano L, Carvalho OP, Barros H (2020) Global cognitive impairment prevalence and incidence in community dwelling older adults—a systematic review. Geriatrics 5(4):84. https://doi. org/10.3390/geriatrics5040084

26. Willig C (2013) Introducing qualitative research in psychology, 3rd edn. Open University Press, Londen

27. Spradley PS (2016) The ethnographic interview. Waveland Press Inc, USA

28. Creswell JW, Creswell JD (2018) Qualitative, quantitative, and mixed methods approaches, 5th edn. SAGE Publications, London

29. Moore S, Leung B, Bates A, Ho C (2018) Social isolation: impact on treatment and survival in patients with advanced cancer. J Clin Oncol 36(34):156. https://ascopubs.org/doi/10.1200/JCO.2018.36. 34_suppl.156

30. Tiedtke CM, Dierckx de Casterlé B, Frings-Dresen MHW, Boer AGEM, Greidanus MA, Tamminga SJ, De Rijk AE (2017) Employers' experience of employees with cancer: trajectories of complex communication. J Cancer Surviv 11(5):562-577. https:// doi.org/10.1007/s11764-017-0626-z

Publisher's note Springer Nature remains neutral with regard to jurisdictional claims in published maps and institutional affiliations. 